\title{
Experimental Studies of Interaction Forces that Affect the Position of Vertical Plates on Oscillating Heave Plates with Cylindrical Bodies in Regular Waves
}

\author{
Eko Sasmito Hadia, ${ }^{a,}$, Muhammad Iqbal $^{\mathrm{a}}$, Ari Wibawa ${ }^{\mathrm{a}}$, Ojo Kurdi ${ }^{\mathrm{b}}$, Karnoto ${ }^{\mathrm{c}}$
}

\author{
a Department of Naval Architecture, Diponegoro University, Indonesia \\ ${ }^{b}$ Department of Mechanical Engineering, Diponegoro University, Indonesia
}

${ }^{c}$ Department of Electrical Engineering, Diponegoro University, Indonesia

\begin{abstract}
This paper discusses an experimental study of a wave energy converter (WEC) without using reaction from the seabed. The WEC uses buoys and heave plates, which can react to their self-reacting. The interaction force between heave plates and buoys can absorb energy from ocean waves better. The heave plate model affects the output of energy produced. It is presented in this study with variations in the position of upright plates. The research aims to measure the influence of the place of the addition of vertical plates into heave plates on the WEC on the hydrodynamic performance (coefficient of mass increase, drag coefficient, and KC value) and the interaction of the force it produces with the buoy on regular waves. The conclusion is the vertical plate position makes the coefficient of mass added $\mathrm{Ca}$ increase with an increasing amount of $\mathrm{KC}$, and an almost linear relationship was observed between them. As the frequency increases, the value of $\mathrm{C}$ increases slightly, but it is not clear. Thus, the oscillating frequency has little effect on the mass coefficient of added heave plates with vertical plates. Thus, the change in the vertical plate position has only a powerful effect on KC $<$ 0.75. C2020. CBIORE-IJRED. All rights reserved
\end{abstract}

Keywords: Wave energy converter, heave plate, coefficient of mass, drag coefficient, buoy

Article History: Received: Oct 17, 2019; Revised: January 10, 2020; Accepted: February 6, 2020; Available online: February 15, 2020

How to Cite This Article: Hadi, E.S., Iqbal, M., Wibawa, A., Ojo, K., and Karnoto (2020). Experimental Studies of Interaction Forces that Affect the Position of Vertical Plates on Oscillating Heave Plates with Cylindrical Bodies in Regular Waves. International Journal of Renewable Energy Development,9(1), 77-84.

https://doi.org/10.14710/ijred.9.1.77-84

\section{Introduction}

Wave energy converters (WECs) that use non-seabed reaction sources, such as heaving plates, which are referred to in the wave energy literature as self-reacting WECs and because the buoy dimensions are relatively small compared with incident wavelengths, can be referred as the point of reaction at the absorber itself. The use of submerged bodies that act as reference actions of floating objects is not a new concept but will have a promising future.

Heave plates are used to transfer the PTO reaction force to the water, which is relatively stationary under WECs. Apart from the critical role played by heave plates in determining the dynamics of WECs and the efficiency of PTO, heave plates have little published research in the context of wave energy.

The dynamics of heave coupling in WECs have been taken into consideration by several authors (Davis, Thomson, Mundon, \& Fabien, 2014; Olaya, Bourgeot, \& Benbouzid, 2013; Rhinefrank et al., 2013; Ruehl, Michelen, Kanner, Lawson, \& Yu, 2014). The dynamics of heave coupling in WECs are taken into consideration by several authors (Davis, Thomson, Mundon, \& Fabien, 2014; Olaya, Bourgeot, \& Benbouzid, 2013; Rhinefrank et al., 2013; Ruehl, Michelen, Kanner, Lawson, \& Yu, 2014). A literature review reveals two patents and no technical papers that specifically focus on heave plates (Bull, Gerber, \& Powers, 2011; US patent no. 20140232116A1, 2014). Heave plates are generally widely used in offshore structures because they can provide additional damping and mass increase to enhance the hydrodynamic response of the system (Zhu \& Lim, 2017). The application of the use of an additional damper plate in the design of a WEC can increase the average annual energy production by $41 \%$ in the case of the point absorber WEC that self-reacts to heave movements in irregular waves (Beatty, Bocking, Bubbar, Buckham, \& Wild, 2019).

Several articles about heave plates and their use have been found. Heave plates have been widely used for the spar platform to suppress heave movements, and then efficient top tensioned risers with dry trees can be used (Tao \& Cai, 2004). Chakrabarti (Chakrabarti, Barnett, Kanchi, Mehta, \& Yim, 2007) designed a truss-pontoon 
semi-submersible platform with eight heave plates to improve dynamic performance.

Halkyard et al., (2002) designed a deep semisubmersible draft with a retractable heave plate. In this design, heave plates are used for additional mass and viscous damping to reduce fluctuations in the floater. $\mathrm{Li}$, Liu, Zhao, \& Teng, (2013) conducted a series of forced oscillation experiments to examine the hydrodynamic coefficients of heave plates. Their results show that the external forced frequency has little effect on the hydrodynamic coefficient when $\mathrm{KC}$ is $0.2-1.2$.

Heave plates that have rectangular edges produce the most significant additional mass. The drag coefficient is almost independent on the shape of the corner. Tian (Tian, Tao, Li, \& Yang, 2017) conducted a series of experiments to investigate the influences of the thickness ratio, shape, edge corner radius, perforation ratio, and hole size on the hydrodynamic coefficients of a single plate. For the twin- and triple-plate configurations, the spacing effects are evaluated.

Carlos et al. conducted a study using numerical calculations, which were used to analyze qualitative vortex release and investigate the relationship between such vortex release and the damping coefficient and pairing mechanisms, such as release angles (Carlos Garrido-Mendoza \& Antonio Souto-Iglesias, 2014). Tao \& Dray, (2008) investigated the added mass and damping of oscillatory solid or porous disks using model-scale experiments. All experiments were conducted via forced oscillation model tests using a planar motion mechanism. The hydrodynamic coefficients of the solid or porous disk obtained from the force measurements were analyzed and presented. The sensitivities of the damping and added mass coefficients to both motion amplitude and disk porosity were examined.

Olaya et al. (Olaya et al., 2013) investigated the hydrodynamic parameter computation of a WEC that consists of a cylindrical buoy sliding along a partially submerged platform made up of a plate and column. The computed parameters particularly needed for the development of a simple hydrodynamic time-dependent model were based on the Cummins' formulation. This model is intended to be used for WEC control purposes.

Beatty et al. (Beatty et al., 2019) conducted an experimental and numerical comparison of the performance of two self-reacting point absorber WEC designs undertaken for heave motions in irregular waves. The results indicate that the WEC design with a damper plate produces $41 \%$ higher mean annual energy production than the WEC design with a streamlined reacting body at a representative location near the west coast of Vancouver Island, British Columbia, Canada.

In the scope of this research project, a WEC prototype using a heave plate system was developed. It will absorb sea wave energy better, especially in coastal or shallow marine environments. This research focused on the characteristics of force resulting from an interaction between a heave plate and a buoy, the coefficient of mass increase $(\mathrm{Ca})$, and the drag coefficient $(\mathrm{Cd})$. Heave plate models using upright plates in various positions are expected to provide good interaction forces, Ca coefficients, and $\mathrm{Cd}$ coefficients.

\section{Materials and Methods}

\subsection{Experimental Setup}

Model tests were carried out in the Hydrodynamics Laboratory of Naval Architecture Department, Diponegoro University. The tank is $13 \mathrm{~m}$ long, $1 \mathrm{~m}$ width, and $1 \mathrm{~m}$ depth. Electric wave makers and a floating beach were installed at the end of the tank and on the other side, respectively. Floating beach are used to minimize wave reflection. Wave makers can be regulated by using an Arduino microcontroller, which moves one flap and can produce sinusoidal waves with varying frequencies up to $6 \mathrm{rad} / \mathrm{s}$ and wave heights up to $150 \mathrm{~mm}$.

Figures 1 and 2 show the experimental settings and photo setup. The heave plate oscillates freely in harmony with the buoy in a vertical direction in water waves. Between heave plates and floats/buoy connected by load cells, to find out the interaction of forces between them. The load cell was placed above the buoy rigidly, and the heave plate was connected using a rigid shaft. The rod and body of the float/buoy were given linear bearings to reduce friction. The force produced by the heave plate on the buoy were recorded by the load cell and then stored on a PC via an Arduino microcontroller. The buoy, which was made from polylactide, has a cylindrical diameter of $0.30 \mathrm{~m}$ and a height of $0.20 \mathrm{~cm}$, and the heave plate, made from acrylic glass, has a diameter of $0.30 \mathrm{~m}$ and thickness of $3 \mathrm{~mm}$. Figure 2 presents an experimental photo setup.

Load cells were used to measure the heave plate force against the buoy (Figure 3). Ultrasonic 1 and ultrasonic 2 were used to measure the height of the buoy motion and surface water waves. An IMU was mounted on the buoy to measure its movement, distance, speed, and acceleration.

The IMU is used to record the movement, speed, and acceleration more accurately (Brown, Thomson, \& Rusch, 2018). The outputs from the load cell, ultrasonic 1, ultrasonic 2, and IMU were recorded through DAQ from Arduino Uno. DAQ from Arduino microcontroller has advantages, such as low cost, open hardware, open source, and modifiability (Hadi, Iqbal, Wibawa, 2018).

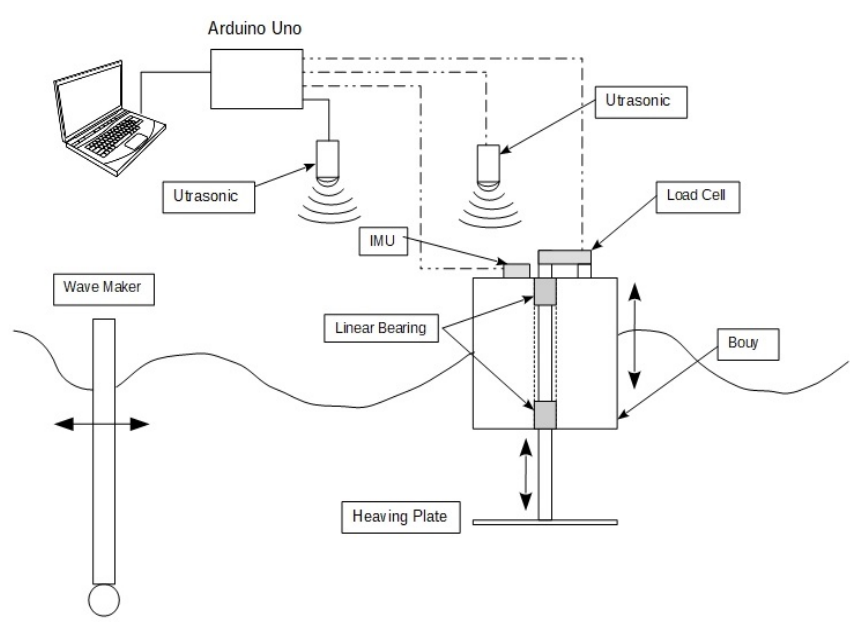

Fig. 1. Experimental setting 


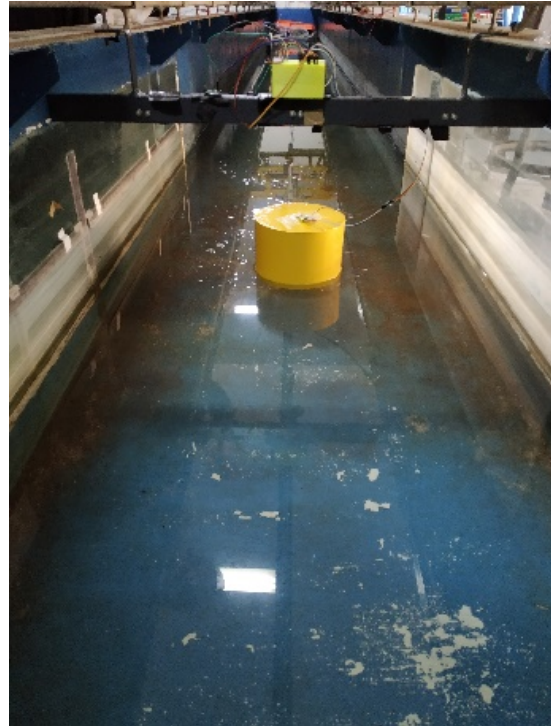

Fig. 2. Experimental photo setup

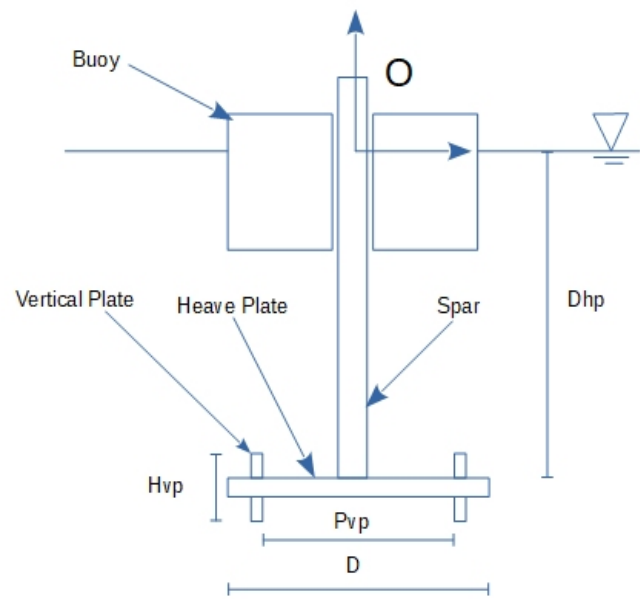

Fig. 3. Definition model of the WEC
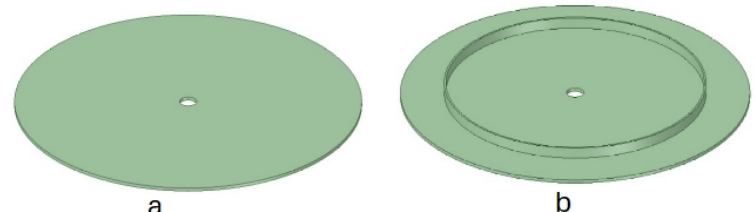

b
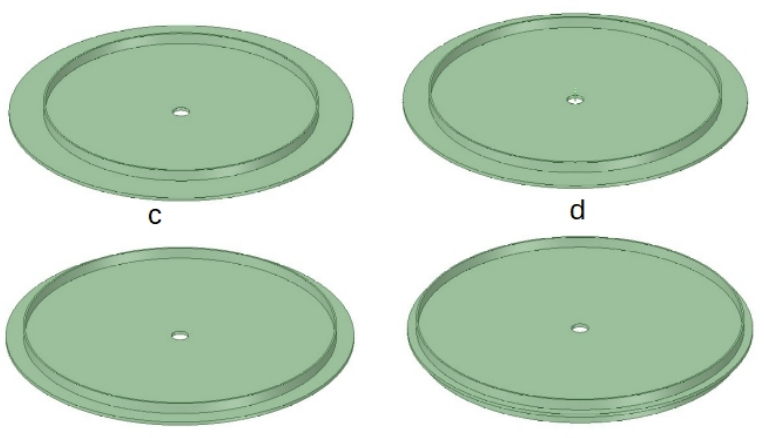

f

Fig. 4. Variation of the vertical position plates on the heave plate: a. Without vertical plate, b. position vertical plate $(0.75$ $\mathrm{D})$, c. position vertical plate $(0.80 \mathrm{D})$, d. position vertical plate $(0.85 \mathrm{D})$, e. position vertical plate $(0.90 \mathrm{D})$, f. position vertical plate $(0.95 \mathrm{D})$
Table 1

Variation of the model heave plate

\begin{tabular}{|cccc}
\hline $\begin{array}{c}\text { Model heave } \\
\text { plate }\end{array}$ & $\begin{array}{c}\text { Width } \\
\text { (D) } \\
\text { (cm) }\end{array}$ & $\begin{array}{c}\text { Position } \\
\text { Vertical plate } \\
\text { (Pvp) (cm) }\end{array}$ & $\begin{array}{c}\text { Height of } \\
\text { vertical plate } \\
\text { (Hvp) (cm) }\end{array}$ \\
\hline $\begin{array}{c}\text { Heave Plate 1 } \\
\text { (Hp 1) }\end{array}$ & 30 & - & - \\
$\begin{array}{c}\text { Heave Plate 2 } \\
\text { (Hp 2) }\end{array}$ & 30 & 0.75 D (22.5) & 2 \\
$\begin{array}{c}\text { Heave Plate } 3 \\
\text { (Hp 3) }\end{array}$ & 30 & 0.80 D (24) & 2 \\
$\begin{array}{c}\text { Heave Plate } 4 \\
\text { (Hp 4) }\end{array}$ & 30 & 0.85 D (25.5) & 2 \\
$\begin{array}{c}\text { Heave Plate 5 } \\
\text { (Hp 5) }\end{array}$ & 30 & 0.90 D (27) & 2 \\
$\begin{array}{c}\text { Heave Plate 6 } \\
\text { (Hp 6) }\end{array}$ & 30 & 0.95 D (28.5) & 2 \\
\hline
\end{tabular}

To investigate the effect of the heave plate force applied to the upright plate on the buoy, the form of variation in the position of the vertical plate at diameters of $0.95 \mathrm{D}, 0.9 \mathrm{D}, 0.85 \mathrm{D}, 0.80 \mathrm{D}$, and $0.75 \mathrm{D}$ was recorded, as shown in Figure 4. Detailed information on the heave plate used is given in Table 1 . The width of the heave plate is the same as the cross-section diameter of the buoy cylinder. Each test lasted for 10-15 cycles and was repeated twice to verify the repetition of experimental results.

\subsection{Data Processing and Analysis}

For the sake of simplicity of the model, the dynamics of the entire structure was limited to the fluctuating modes in the z-axis direction. Assuming the linear potential wave theory applied, the linear motion equation in the heaving plate model is given in the coordination of the reference frame at point $\mathrm{O}$ located at the intersection of the free surface level with a regular wave interference with the positive cylinder axis and z-axis upward (Figure 2). From Newton's second law and using matrix notations:

$$
\begin{gathered}
M \ddot{z}(t)=F(t), \\
\left(M_{33}+A_{33}\right) \ddot{z}+b \dot{z}+\rho g A_{w p} z \approx F_{z},
\end{gathered}
$$

where $\mathrm{M}_{33}, \mathrm{~A}_{33}, \mathrm{~b}$, and $\mathrm{F}$ are the mass, heave added mass, linearized damping coefficient, and force in the $\mathrm{z}$ direction, respectively. In addition, $\rho$, g, and Awp are the density of water, acceleration of gravity, and water plane area, respectively.

$$
F(z) \approx F_{e x}(t)+F_{r}(t)+F_{S}(t)
$$

$\mathrm{F}_{\mathrm{Z}}$ is a general force vector expressed in several components, $F_{\text {ex }}$ is the wave excitation force, $F_{r}$ is the force associated to the radiation problem, and $F_{s}$ is the net restoring force due to gravity and buoyancy.

According to the Morison equation (T. Sarpkaya, 1981), the equation of motion of the plate system can be represented by

$$
F(z)=\left(M+\rho \nabla C_{a}\right) \ddot{x}+\frac{1}{2} \rho A C_{d} \dot{x}|\dot{x}|,
$$


where $M$ is the mass of the system, $\rho$ is the density of water, $\nabla$ is the immersed volume of the plate including the connecting rod, $\mathrm{A}$ is the area of the plate, $\mathrm{Ca}$ is the added mass coefficient, and $\mathrm{Cd}$ is the drag coefficient. $\mathrm{x}$, $\dot{x}$, and $\ddot{x}$ are the displacement, velocity, and acceleration, respectively, of the forced motion.

FZ is the total force on the plate system, which is recorded by the load cell. In the present study of thin plates "force self-reacting" to oscillate in water, $\nabla$ is defined as the volume of the "equivalent" cube, i.e., $\nabla=\mathrm{A} \mathrm{x}$ $\mathrm{D}$, where D represents the width of the heave plate.

The temporal location and force of the test model can be formulated as follows:

$$
\begin{gathered}
z(t)=A_{z} e^{i \omega t}=A_{z}(\cos \omega t+i \sin \omega t) \\
F_{z}(t)=A_{F} e^{i \omega t}=A_{F}(\cos \omega t+i \sin \omega t)
\end{gathered}
$$

By substituting Eqs. (5) and (6) into Eq. (2) and taking real parts, the functions can then be rewritten as follows:

$$
\begin{aligned}
z(t) & \approx A_{z} \sin \left(\omega t+\varepsilon_{z}\right), \\
F_{z}(t) & \approx A_{F} \sin \left(\omega t+\varepsilon_{F}\right),
\end{aligned}
$$

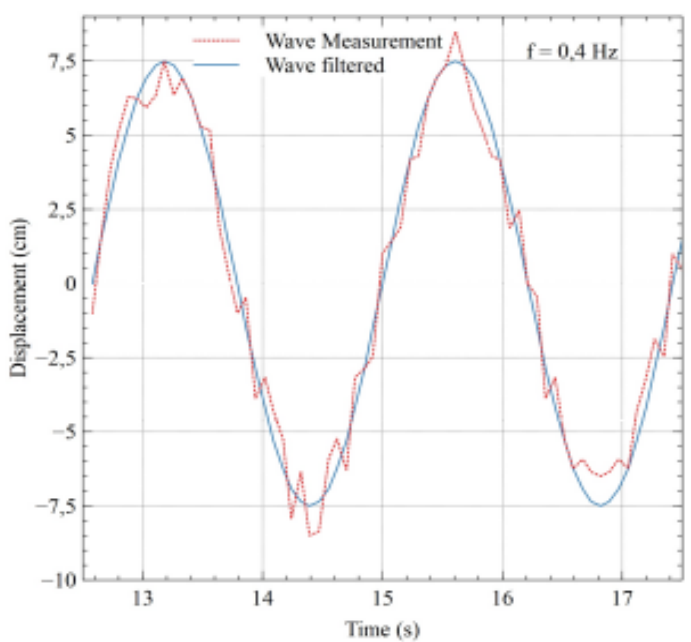

where $\mathrm{Az}$ and $\mathrm{AF}$ are the amplitude of the periodic motion and total force self-reacting, respectively, and $\varepsilon z$ and $\varepsilon F$ represent the diff erent phases in the periodic motion and its corresponding self-reacting strength. An IMU and load cell can measure this regular motion and self-reacting power.

During testing, the load cell records the time history of the force heave plate, and the ultrasonic and IMU recorded the time history of the displacement of the buoy. The speed and acceleration time series can calculate distinguishing movements, one and two times each. Thus, only two variables are unknown, namely, $\mathrm{Ca}$ and $\mathrm{Cd}$, in Eq. (2). They can be derived using the leastsquares method according to the force, displacement, speed, and time series, which were derived from Eq. (2).

Due to the frequency noise from the wave maker and ultrasonic gauge, the outputs from the instruments were filtered using the Fourier transform method. Figure 5 gives the typical measured and filtered time histories of the wave elevation and buoy displacement. It also shows that this filtering method could effectively remove the noise.

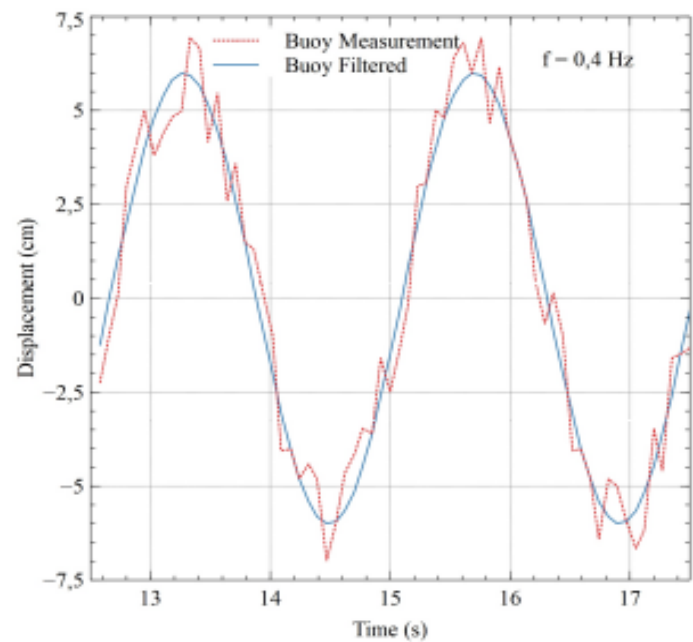

Fig. 5. Typical time histories of wave and buoy displacements

The hydrodynamic forces on the oscillating plate in still water depend on two fundamental non-dimensional parameters, which are defined as

$$
\begin{gathered}
K C=\frac{2 \pi a}{D}, \\
\beta=\frac{D^{2} f}{v},
\end{gathered}
$$

where $\mathrm{D}$ is the width of the heave plate; $a$ and $f$ are the amplitude and frequency of the oscillation, respectively; and $v$ is the kinematic viscosity of the fluid.

\section{Results and Discussion}

The hydrodynamic coefficients of the heave plate model, including the added mass coefficient $\mathrm{Ca}$ and the drag coefficient $\mathrm{Cd}$, can be obtained by the least-squares method for all test cases. The effects of the different parameters and the results are summarized below.
3.1 Influence of the Vertical Plate Position, KC Number, and Added Mass Coefficient.

Table 2

Experimental parameters

\begin{tabular}{cccc}
\hline $\begin{array}{c}\text { Model heave } \\
\text { plate }\end{array}$ & $\begin{array}{c}\text { Freq. of } \\
\text { oscillation } \\
\text { wave maker } \\
\text { (Hz) }\end{array}$ & $\begin{array}{c}\text { Depth of } \\
\text { the heave } \\
\text { plate } \\
\text { (Dhp) }(\mathbf{c m})\end{array}$ & Pvp \\
\hline $\begin{array}{c}\text { Heave Plate 1 } \\
\text { (Hp 1) }\end{array}$ & $0.2-0.8$ & 50 & - \\
$\begin{array}{c}\text { Heave Plate } 2 \\
\text { (Hp 2) }\end{array}$ & $0.2-0.8$ & 50 & $0.75 \mathrm{D}$ \\
$\begin{array}{c}\text { Heave Plate } 3 \\
\text { (Hp 3) }\end{array}$ & $0.2-0.8$ & 50 & $\begin{array}{c}(22.5 \mathrm{~cm}) \\
0.80 \mathrm{D} \\
(24 \mathrm{~cm})\end{array}$ \\
$\begin{array}{c}\text { Heave Plate } 4 \\
\text { (Hp 4) }\end{array}$ & $0.2-0.8$ & 50 & $0.85 \mathrm{D}$ \\
Heave Plate 5 & $0.2-0.8$ & 50 & $\begin{array}{c}25.5 \mathrm{~cm}) \\
\text { (Hp 5) }\end{array}$ \\
$\begin{array}{c}\text { Heave Plate 6 } \\
\text { (Hp 6) }\end{array}$ & $0.90-0.8$ & 50 & $\begin{array}{c}27 \mathrm{~cm}) \\
0.95 \mathrm{D}\end{array}$ \\
\hline
\end{tabular}



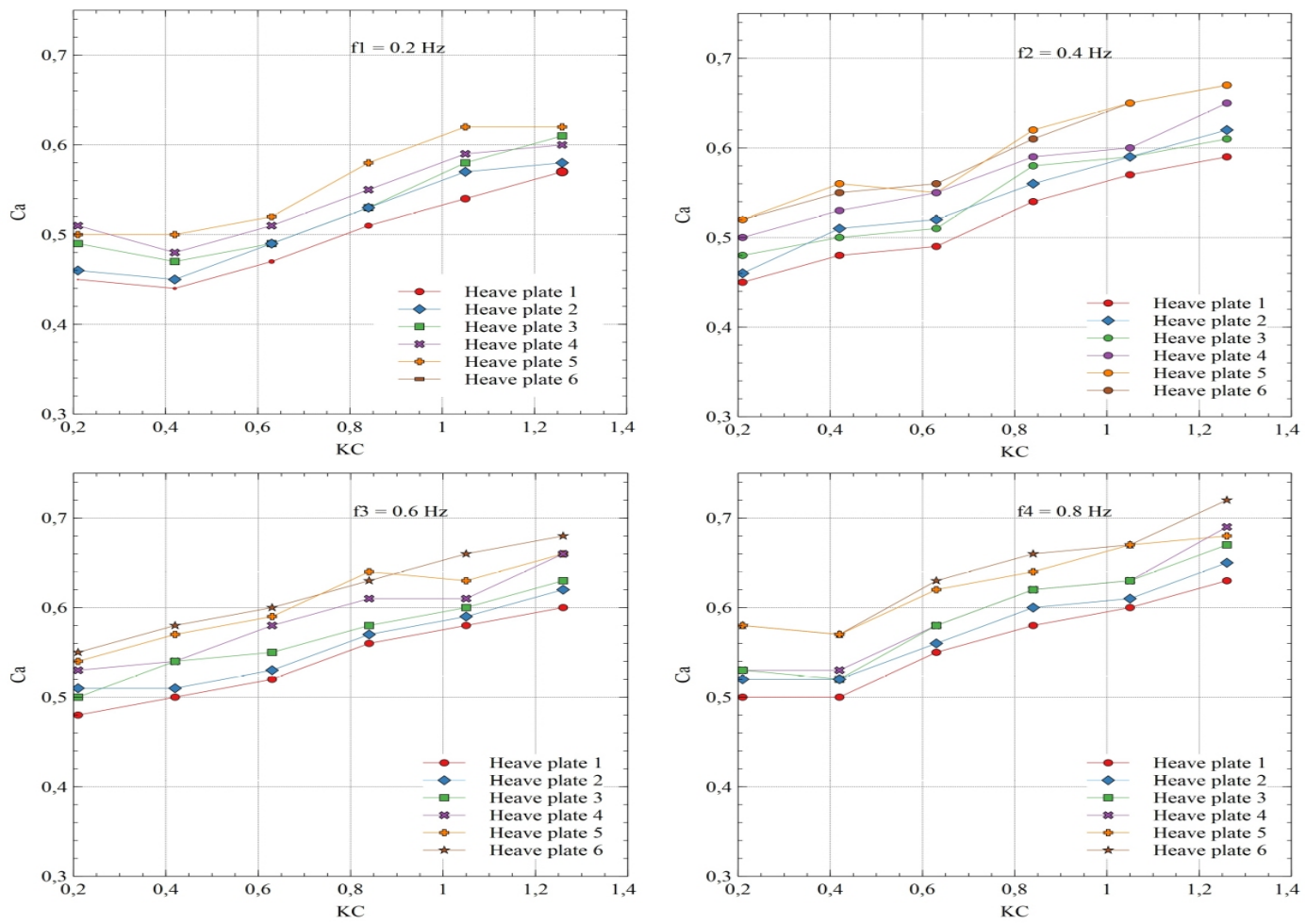

Fig. 6. Ca values on all heave plate variations against $\mathrm{KC}$ at frequencies $0.2,0.4,0.6$, and 0.8 .

To test the effect of the upright plate position on the heave plate experimental results and the validity of the experimental results, experiments on all heave plate variations were carried out at the same depth. Because the width of plate $\mathrm{D}$ remains constant, the $\mathrm{KC}$ number represents the amplitude of the oscillation. As shown in Eq. (2) and Table 2, testing on all heave plate variations was carried out using $\mathrm{KC}$ numbers in the range of $0.2-$ 1.3 , which is typical of the vertical oscillations of deepsea offshore structures. The test oscillation frequencies varied within the range $0.2-0.8 \mathrm{~Hz}$, corresponding to $B=$ 29,090-160,000.

Figure 6 gives an additional mass coefficient of all variations of the heave plate, at the same depth, to observe the effect of the upright plate position. The Ca values at all frequencies show the same change characteristics too. The added mass coefficient Ca increases with increasing $\mathrm{KC}$ number, and a nearly linear relationship was observed between them. As the frequency increases, the value of $\mathrm{Ca}$ increases slightly, but it is not apparent. Thus, the oscillating frequencies have only a slight influence on the added mass coefficient of a heave plate. The value of $\mathrm{Ca}$ on heave plate 1 is relatively lower in all frequencies and heave plate 6 has higher values in all frequencies. An increasing trend of $\mathrm{Ca}$ values was observed at each $\mathrm{KC}$ value for all heave plate models, similar to the results of Zhu and Lim's experiments (Zhu \& Lim, 2017). This trend is inversely proportional to the problem on the heave plate being given a hole as proposed by (Li et al., 2013).

\subsection{Influence of the Vertical Plate Position, KC Number, and Drag Coefficient}

In contrast to the added mass coefficient $\mathrm{Ca}$, the drag coefficient $\mathrm{Cd}$ decreases with an increasing amount of $\mathrm{KC}$ on all heave plate model variations, as shown in Figure 6 . Cd values rapidly fall when $\mathrm{KC}<0.75$, and they tend to be constant for $\mathrm{KC}$ values $>0.75$.

Figure 6 shows the drag coefficients of all heave plate models at the same depth, having identical characteristics. Heave plate 1 has the features of $\mathrm{Cd}$ values on all $\mathrm{KC}$ values similar, as stated by $\mathrm{Li}$ et al., (2013). The $\mathrm{Cd}$ value for heave plate 1 has a relatively small amount compared with the others, which is due to the absence of upright plates attached to the heave plate.

The difference in the position of the upright plate on the heave plate affects the value of $\mathrm{Cd}$, which becomes smaller and relatively constant at $\mathrm{KC}>0.75$ for all variations of the heave plate model. At $\mathrm{KC}<0.75, \mathrm{Cd}$ strongly shows an exponential decrease. The decrease in the $\mathrm{Cd}$ value is relatively exponential to the $\mathrm{KC}$ value, similar to that stated by Liang, Liu, Li, \& Ou, (2018). This difference in value is inversely proportional to the problem of a heave plate that is given in a hole ( $\mathrm{Li}$ et al., 2013). 
Moreover, the drag coefficient does not depend entirely on the oscillating frequency. However, the effect of oscillating frequency on the drag coefficient is small and can be ignored. The observation of the effects of frequency on this Cd has given by Tao \& Dray, (2008). The reason may be that in the $\mathrm{KC} 0.2-1.2$, convection is the dominant feature in the flow produced by oscillating plates and is only slightly related to frequency.

Therefore, the main effect factor for the hydrodynamic coefficient, $\mathrm{Ca}$ and $\mathrm{Cd}$, is the $\mathrm{KC}$ number. The reason may be because the $\mathrm{KC}$ number characterizes the amplitude of fluid motion relative to the heave plate parameters and amplitude of the heave plate motion.

The vortex release around the plate occurs when the plate oscillates, which affect the hydrodynamic coefficient. Tao \& Thiagarajan, (2003) observed three modes of vortex shedding, namely, independent, interactive and asymmetrical unidirectional vortex shorting, with the numerical investigation of oscillating cylinders with single disks of different thicknesses. The occurrence of the vortex shedding mode is shown mainly depending on the $\mathrm{KC}$ number and heave plate dimensions.

Of note, the minimum frequency used in this paper is $0.2 \mathrm{~Hz}$. However, as Tao and Dray (Tao \& Dray, 2008) mentioned, when the $\mathrm{KC}$ number is deficient, the flow around the edges of the plate is dominated by diffusion. The results will depend on the frequencies of oscillations because the dominance of diffusion is related to the frequency. He, (2003) showed experimentally that, for solid disks, the damping coefficient varies with the frequency when $\mathrm{KC}<0.1$.
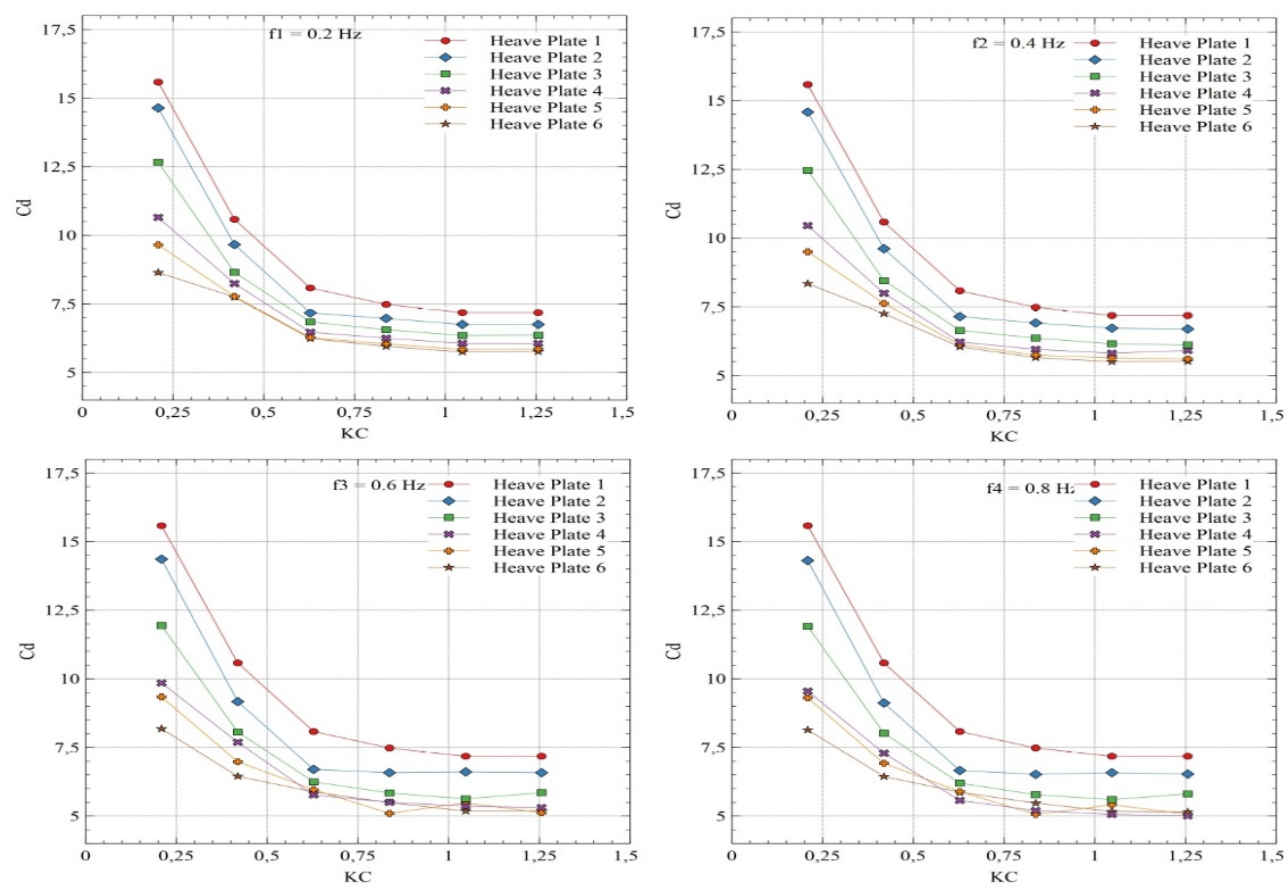

Fig. 7. Ca values on all heave plate variations against $\mathrm{KC}$ at frequencies $0.2,0.4,0.6$, and 0.8 .

\subsection{Influence of the vertical plate position, KC number, and drag coefficient}

In contrast to the added mass coefficient $\mathrm{Ca}$, the drag coefficient $\mathrm{Cd}$ decreases with an increasing amount of $\mathrm{KC}$ on all heave plate model variations, as shown in Figure 6. Cd values fall rapidly when $\mathrm{KC}<0.75$ and they tend to be constant for $\mathrm{KC}$ values $>0.75$.

Figure 8 shows the time history of the force (for the six disks) and the displacement in one oscillation period at a frequency of $0.4 \mathrm{~Hz}$ and a sum of $\mathrm{KC}$ of 0.2 . An interaction force trends from the heave plates and buoy, following the contour lines of a water wave. The phase shift of the water wave and buoy movement is influenced by the inertia value of the floats at approximately 0.1 seconds. The phase shift of the force produced by the heave plate to the buoy is influenced by the coefficients of $\mathrm{Ca}$ and $\mathrm{Cd}$ due to the position of the upright plate. The figure shows that, at this frequency and relatively small amplitude, a phase shift occurs due to changes in the position of the upright plate on the heave plate. The phase difference between the solid heave plate (Hp1) force and displacement is only approximately 0.1 seconds, whereas the heave plate with the upright plate (Hp6) shows a phase difference of approximately 0.25 seconds between the movement and the total measured strength. The phase difference due to the position of the upright plate on the heave plate affects the vortex produced around it, as revealed by $\mathrm{He}$ (He, 2003).

The position of the upright plate on the heave plate affects the oscillation forces generated on the buoy. The location of the vertical plate is getting closer to the outer diameter of the heave plate, and then the oscillation force produced is more significant. This is shown between the results of Hp 1 and Hp 6 around 15\%. 


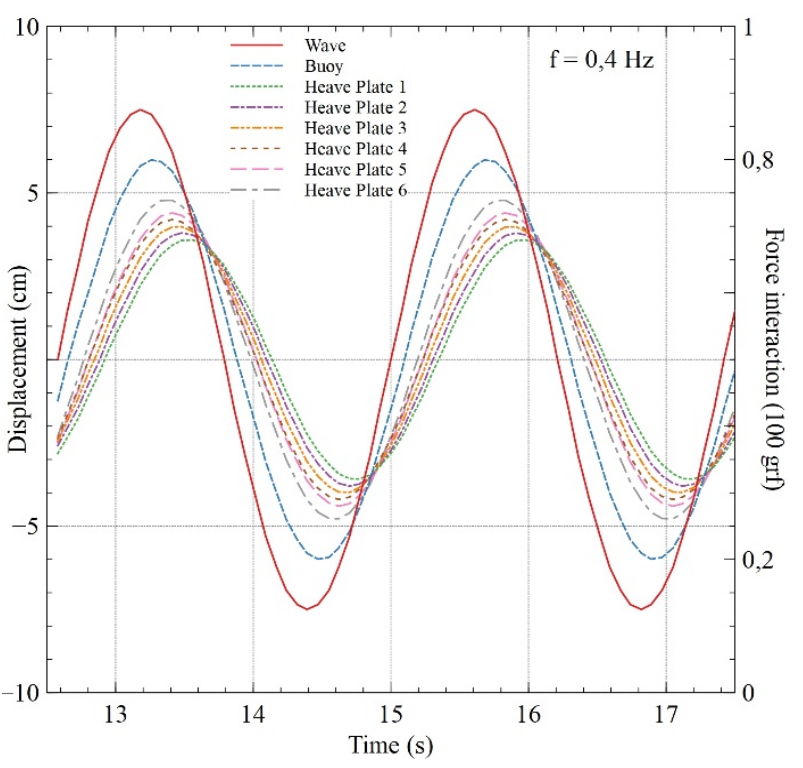

Fig. 8. Measurement results among waves, buoys, and the interaction force of the heave plate

The line characteristics in Figure 8 are also similar to the research conducted by (Tao \& Dray, 2008), who said that the phase angle is critical in determining the energy transfer to the fluid because of the small magnitude of the damping force.

\section{Conclusion}

The effects of different variables on the hydrodynamic coefficient are analyzed. The conclusion is as follows: The vertical plate position makes the coefficient of mass added $\mathrm{Ca}$ increase with an increasing amount of $\mathrm{KC}$, and an almost linear relationship was observed between them. As the frequency increases, the value of $\mathrm{C}$ increases slightly, but it is not clear. Thus, the oscillating frequency has little effect on the mass coefficient of added heave plates with vertical plates.

The difference in the position of the vertical plate on the heave plate affects the value of $\mathrm{Cd}$, which becomes smaller and relatively constant at $\mathrm{KC}>0.75$ for all variations of the heave plate model. At $\mathrm{KC}<0.75, \mathrm{Cd}$ strongly shows an exponential decrease. Thus, the change in the vertical plate position has only a powerful effect on $\mathrm{KC}<0.75$.

\section{Acknowledgments}

The authors thank the reviewers for their constructive suggestions and comments that helped improve this research paper and the authors would like to express their gratitude to the Ministry of Research, Technology, and Higher Education for the support of this research with the research contract No. 101-38/UN7.P4.3/PP/2019 and Department of Naval Architecture, Faculty Engineering, Diponegoro University.

\section{References}

Beatty, S. J., Bocking, B., Bubbar, K., Buckham, B. J., \& Wild,
P. (2019). Experimental and numerical comparisons of self-reacting point absorber wave energy converters in irregular waves. Ocean Engineering, 173, 716-731.

Brown, A., Thomson, J., \& Rusch, C. (2018). Hydrodynamic Coefficients of Heave Plates, with Application to Wave Energy Conversion. IEEE Journal of Oceanic Engineering, 43(4), 983-996.

Bull, D., Gerber, J., \& Powers, W. (2011). Heave plate with improved characteristics. Google Patents.

Carlos Garrido-Mendoza, Antonio Souto-Iglesias, K. T. (2014). Numerical Investigation of the Flow Features Around Heave Plates Oscillating Close to a Free Surface or Seabed. In ASME (Ed.), 33rd International Conference on Ocean, Offshore and Arctic Engineering (OMAE), 2014.

Chakrabarti, S., Barnett, J., Kanchi, H., Mehta, A., \& Yim, J. (2007). Design analysis of a truss pontoon semisubmersible concept in deep water. Ocean Engineering, 34(3-4), 621-629.

Davis, A. F., Thomson, J., Mundon, T. R., \& Fabien, B. C. (2014). Modeling and Analysis of a Multi Degree of Freedom Point Absorber Wave Energy Converter. In Volume 8A: Ocean Engineering. American Society of Mechanical Engineers.

Eko Sasmito Hadi, M Iqbal, Ari Wibawa, K. (2018). Experimental Measurement of Floating Structure Motion Response Based on the Low-Cost Microcontroller in Towing Tank Laboratory. International Journal of Mechanical Engineering and Technology (IJMET, 9(10), 614-624.

Halkyard, J., Chao, J., Abbott, P., Dagleish, J., Banon, H., \& Thiagarajan, K. (2002). A Deep Draft Semisubmersible with a Retractable Heave Plate. Offshore Technology Conference. Houston, Texas: Offshore Technology Conference. https://doi.org/10.4043/14304-MS

He, H. (2003). Hydrodynamics of Thin Plates. Ph.D. Thesis. Department of Naval Architecture and Marine Engineering. The University of Michigan.

James M Thomson, Joseph L Talbert, Alex Deklerk, Curtis Rusch, Z. M. (2014). US Patent no $20140232116 A 1$.

Li, J., Liu, S., Zhao, M., \& Teng, B. (2013). Experimental investigation of the hydrodynamic characteristics of heave plates using forced oscillation. Ocean Engineering, 66, 8291. https://doi.org/10.1016/j.oceaneng.2013.04.012

Liang, H. zhi, Liu, K., Li, L. yu, \& Ou, J. ping. (2018). Dynamic Performance Analysis of the Tuned Heave Plate System for Semi-Submersible Platform. China Ocean Engineering, 32(4), 422-430.

Olaya, S., Bourgeot, J. M., \& Benbouzid, M. (2013). Hydrodynamic coefficients and wave loads for a WEC device in heaving mode. In OCEANS 2013 MTS/IEEE Bergen: The Challenges of the Northern Dimension.

Rhinefrank, K., Schacher, A., Prudell, J., Cruz, J., Stillinger, C., Naviaux, D., ... Cox, D. (2013). Numerical Analysis and Scaled High Resolution Tank Testing of a Novel Wave Energy Converter. Journal of Offshore Mechanics and Arctic Engineering, 135(4).

Ruehl, K., Michelen, C., Kanner, S., Lawson, M., \& Yu, Y. H. (2014). Preliminary verification and validation of WECSIM, an open-source wave energy converter design tool. In Proceedings of the International Conference on Offshore Mechanics and Arctic Engineering - OMAE (Vol. 9B).

T.Sarpkaya, M. I. (1981). Mechanics of Wave Forces on Offshore Structures. New York: van Nostrand Reinhold.

Tao, L., \& Cai, S. (2004). Heave motion suppression of a Spar with a heave plate. Ocean Engineering, 31(5), 669-692.

Tao, L., \& Dray, D. (2008). Hydrodynamic performance of solid and porous heave plates. Ocean Engineering, 35(10), 1006-1014.

Tao, L., \& Thiagarajan, K. (2003). Low KC flow regimes of oscillating sharp edges I. Vortex shedding observation. Applied Ocean Research, 25(1), 21-35. 
Citation: Hadi, E.S., Iqbal, M., Wibawa, A., Ojo, K., and Karnoto (2020). Experimental Studies of Interaction Forces that Affect the Position of Vertical Plates on Oscillating Heave Plates with Cylindrical Bodies in Regular Waves. Int. Journal of Renewable Energy Development, 9(1), 77-84, doi.org/10.14710/ijred.9.1.77-84

$\mathrm{P}$ a g e $\mid 84$

Tian, X., Tao, L., Li, X., \& Yang, J. (2017). Hydrodynamic coefficients of oscillating flat plates at $0.15 \leqslant \mathrm{KC} \leqslant 3.15$. Journal of Marine Science and Technology, 22(1), 101-
113.

Zhu, L., \& Lim, H.-C. (2017). Hydrodynamic characteristics of a separated heave plate mounted at a vertical circular cylinder. Ocean Engineering, 131, 213-223. 